Article

\title{
Catalytic Pyrolysis of Polyethylene and Polypropylene over Desilicated Beta and Al-MSU-F
}

\author{
Hyung Won Lee $₫$ and Young-Kwon Park * \\ School of Environmental Engineering, University of Seoul, Seoul 02504, Korea; adexhw@nate.com \\ * Correspondence: catalica@uos.ac.kr; Tel.: +82-2-6490-2870
}

Received: 3 October 2018; Accepted: 24 October 2018; Published: 26 October 2018

\begin{abstract}
The catalytic pyrolysis (CP) of different thermoplastics, polyethylene (PE) and polypropylene (PP), over two types of mesoporous catalysts, desilicated Beta (DeBeta) and Al-MSU-F (AMF), was investigated by thermogravimetric analysis (TGA) and pyrolyzer-gas chromatography/mass spectrometry (Py-GC/MS). Catalytic TGA of PE and PP showed lower decomposition temperatures than non-catalytic TGA over both catalysts. Between the two catalysts, DeBeta decreased the decomposition temperatures of waste plastics further, because of its higher acidity and more appropriate pore size than AMF. The catalytic Py-GC/MS results showed that DeBeta produced a larger amount of aromatic hydrocarbons than AMF. In addition, CP over AMF produced a large amount of branched hydrocarbons.
\end{abstract}

Keywords: catalytic pyrolysis; waste plastic; desilicated Beta

\section{Introduction}

The excessive use of synthetic plastics has led to the accelerated increase in waste plastics. Although the recycling of waste plastics is considered appropriate for the resource circulation society, many of them are still landfilled or incinerated, because the material recycling of many plastics is still difficult due to the large content of other impurities, such as pigments, paper, and alumina, in the waste plastics. The landfill and incineration of waste plastics is undesirable, owing to its non-biodegradability and harmful gas emissions. Therefore, many countries have prohibited these two treatment technologies, and are emphasizing the recycling of waste plastics. On the other hand, the effective recycling of waste plastics is limited by the economical barrier caused by the low quality of recycled waste plastics [1-5]. Therefore, many researchers and industries are considering the use of waste plastics as a source of fuel or chemical feedstock. The high heating value of consumable plastics also suggests the potential value of waste plastics as a source of energy or fuel recovery [6,7]. In this aspect, pyrolysis, a thermal decomposition reaction of plastics at temperatures between 400 and $600{ }^{\circ} \mathrm{C}$ under oxygen free conditions [8-11], can be considered an appropriate method for both the treatment of waste plastics and the production of fuel or chemical feedstock from waste plastics. Although a large quantity of hydrocarbons can be produced by the pyrolysis of waste plastics, the product quality of waste plastics pyrolysis differs according to the type of plastic. Among the various types of waste plastic, polyethylene (PE) and polypropylene (PP) are difficult to be converted to proper fuel or chemical feedstock by simple pyrolysis, because most PE and PP pyrolysis products consist of low quality wax with a wide carbon number distribution $(\geq \mathrm{C} 30)$ [12], and need to be upgraded by applying an additional process. Catalytic pyrolysis (CP) of PE and PP can not only allow a decrease in the pyrolysis reaction temperature, but also produce high product quality. Zhang et al. [13] reported that the decomposition temperature of waste plastics can be lowered using a catalyst, because catalytic cracking can decrease the overall activation energy required for the decomposition of plastics. 
Auxilio et al. [14] produced high quality oil with a large amount of aromatic hydrocarbons by applying $\mathrm{CP}$ to waste plastics.

During recent decades, many types of catalysts, such as commercial zeolites (HY, HBeta, and HZSM-5), spent FCC, red mud from alumina refineries, and natural minerals $\left(\mathrm{CaCO}_{3}\right.$ and $\left.\mathrm{NaCO}_{3}\right)$, have been used in the $\mathrm{CP}$ of various types of waste plastics in municipal solid waste (MSW), such as high density PE (HDPE), low density PE (LDPE), PP, polyethylene terephthalate (PET), polystyrene (PS), and polyvinylchloride (PVC) [15-17]. On the other hand, the lower conversion rate to valuable products and/or rapid catalyst deactivation limits their actual commercialization.

Recently, many researchers have considered the use of other catalysts to increase the reaction efficiency, decrease catalyst deactivation, or provide cost effectiveness during CP. Sun et al. [18] reported the catalytic pyrolysis of mixed plastics (PE, PP, PS) using activated biochar catalysts treated with $\mathrm{ZnCl}_{2}, \mathrm{KOH}$, and $\mathrm{H}_{3} \mathrm{PO}_{4}$ to modify the acid properties and pore structure of the activated biochar surface, and obtained high quality oil with high aromatic selectivity over $\mathrm{H}_{3} \mathrm{PO}_{4}$-treated activated biochar with a higher mesopore ratio and Lewis/Brønsted acid sites. Ratnasari et al. [19] applied a mesoporous material, Al-MCM-41, to the CP of waste plastics, and produced oil with a similar carbon number distribution to gasoline. Santos et al. [20] also produced high quality oil with a high olefin contents by applying alkaline and acid-treated zeolites, such as HZSM-5, $\mathrm{NH}_{4} \mathrm{ZSM}-5$, and USY, to the $\mathrm{CP}$ of PE and PP mixtures. They explained that the mesoporosity of zeolite, increased by the alkaline and acid treatment, can improve the overall cracking efficiency because of the easier access of reactant molecules to the acid sites inside the catalyst pores. On the other hand, there are few reports of other types of mesoporous catalysts, such as desilicated mesoporous HBeta (DeBeta) and Al-MSU-F (AMF).

DeBeta is a mesoporous zeolite made by the desilication of microporous Beta. Although its use on the $\mathrm{CP}$ of waste plastics can be assumed to be effective because of its increased mesoporosity and high acidity, its actual application to the $\mathrm{CP}$ of waste plastics has not been evaluated.

In this study, the CP of waste plastics, HDPE and PP, over DeBeta and AMF, was performed. The catalytic activity of DeBeta and other types of mesoporous catalyst (AMF) was assessed by comparing the decomposition temperatures of HDPE and PP over the catalysts and estimating the product quality obtained from the iso-thermal $\mathrm{CP}$ of waste plastics by thermogravimetric analysis (TGA) and pyrolysis-gas chromatography/mass spectrometry (Py-GC/MS).

\section{Results and Discussion}

Figure 1 presents the $\mathrm{N}_{2}$ adsorption-desorption isotherm results of the catalysts. The $\mathrm{N}_{2}$ adsorption-desorption isotherm of catalysts exhibited typical type-IV isotherms with hysteresis loops, which is characteristic of mesoporous catalysts. Both catalysts, DeBeta and Al-MSU-F, had different hysteresis loops due to differences in the pore structure. 


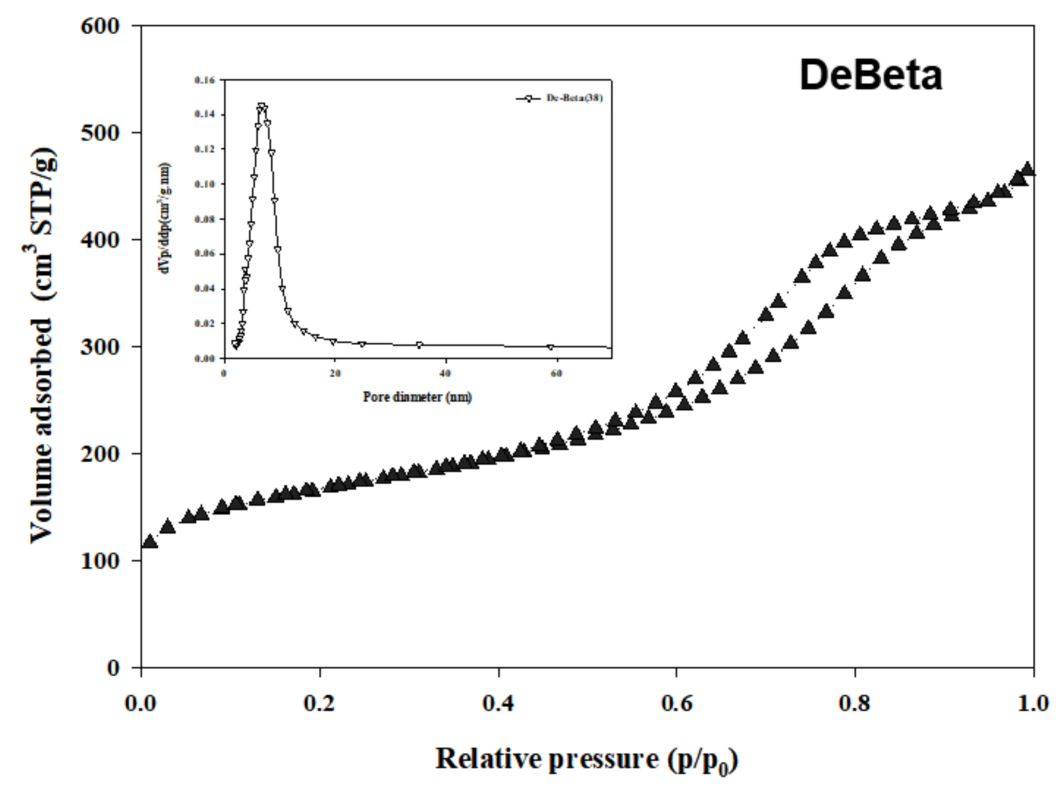

(a)

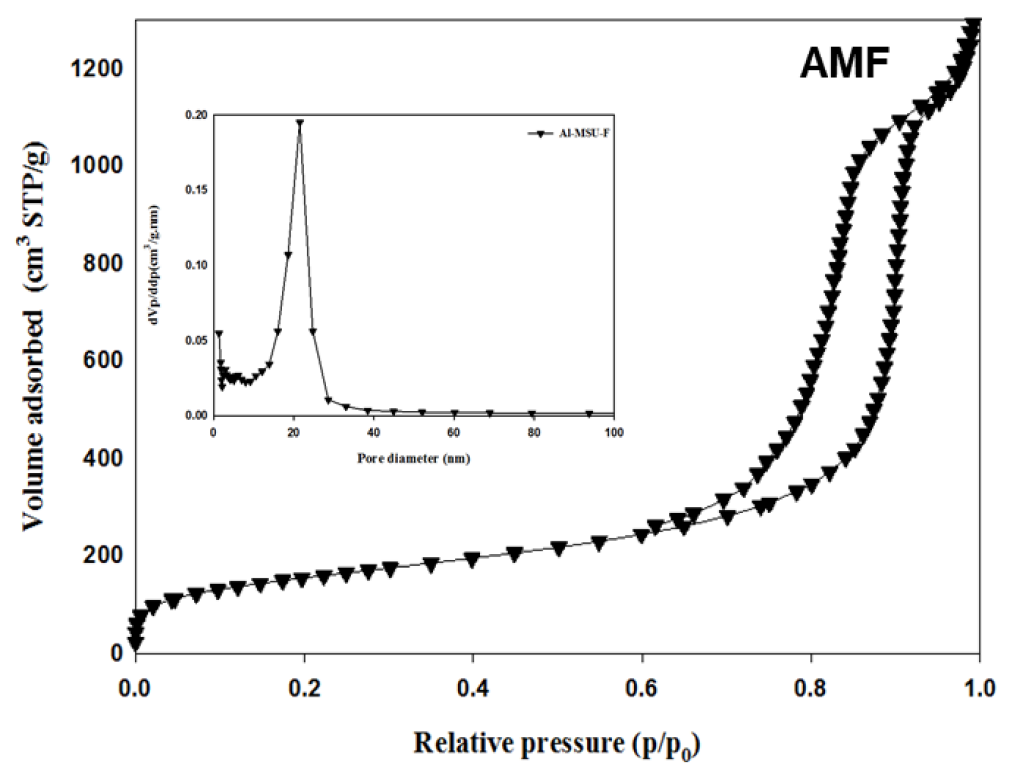

(b)

Figure 1. $\mathrm{N}_{2}$ adsorption-desorption isotherm of (a) DeBeta and (b) AMF.

The mean pore size, pore volume, and specific surface area of DeBeta and AMF were $48 \AA$, $0.72 \mathrm{~cm}^{3} / \mathrm{g}$, and $602 \mathrm{~m}^{2} / \mathrm{g}$; and $140 \AA, 1.97 \mathrm{~cm}^{3} / \mathrm{g}$, and $561 \mathrm{~m}^{2} / \mathrm{g}$, respectively. DeBeta had a larger specific surface area and smaller pore size and pore volume than AMF. Although the pore size of DeBeta was smaller than that of AMF, it was larger than that of the parent Beta, due to the desilication treatment. The X-ray diffraction (XRD) peak intensity of DeBeta was lower than that of the parent Beta, owing to the partial elimination of Si from the zeolite frame due to desilication [21] (Figure 2a). Figure $2 b$ showed XRD pattern of AMF having 2-D hexagonal pore structure diffraction patterns. The curves of $\mathrm{NH}_{3}$-TPD analysis, shown in Figure 3, indicated that DeBeta had higher acidity than AMF. 


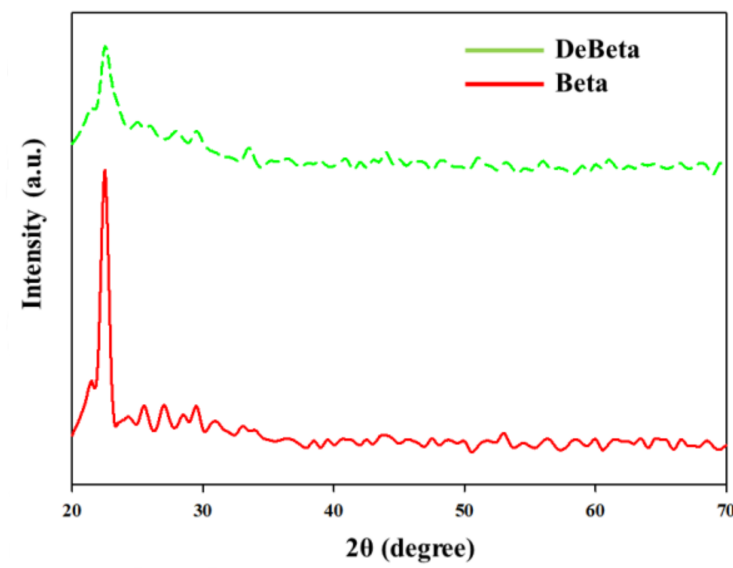

(a)

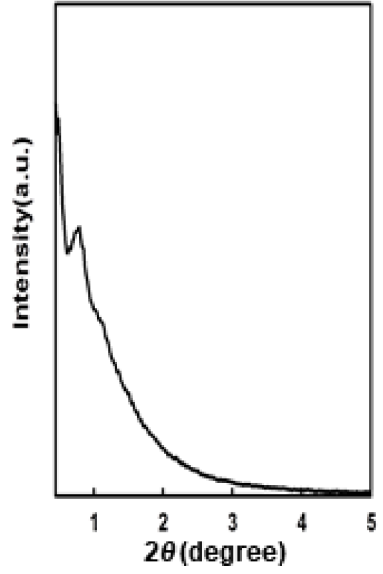

(b)

Figure 2. XRD patterns of (a) Beta, DeBeta and (b) AMF.

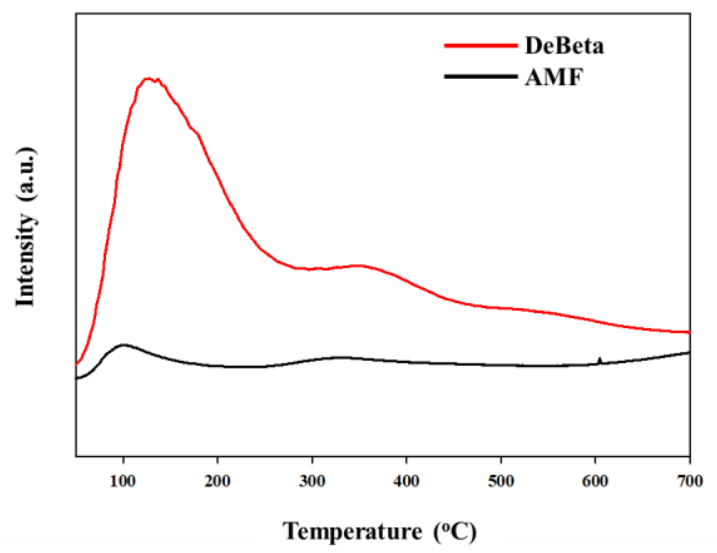

Figure 3. $\mathrm{NH}_{3}-\mathrm{TPD}$ curves of DeBeta and AMF.

Figure 4 presents the derivative TG (DTG) results for the thermal and catalytic TGA of HDPE and PP over DeBeta and AMF. 


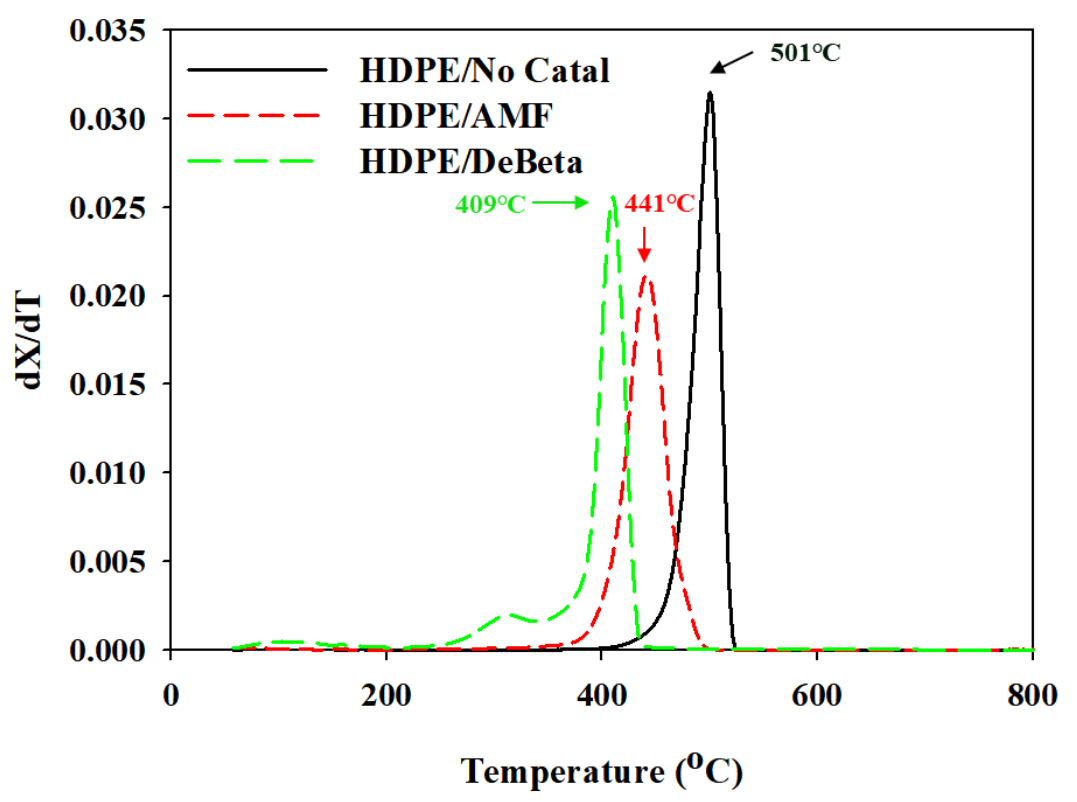

(a)

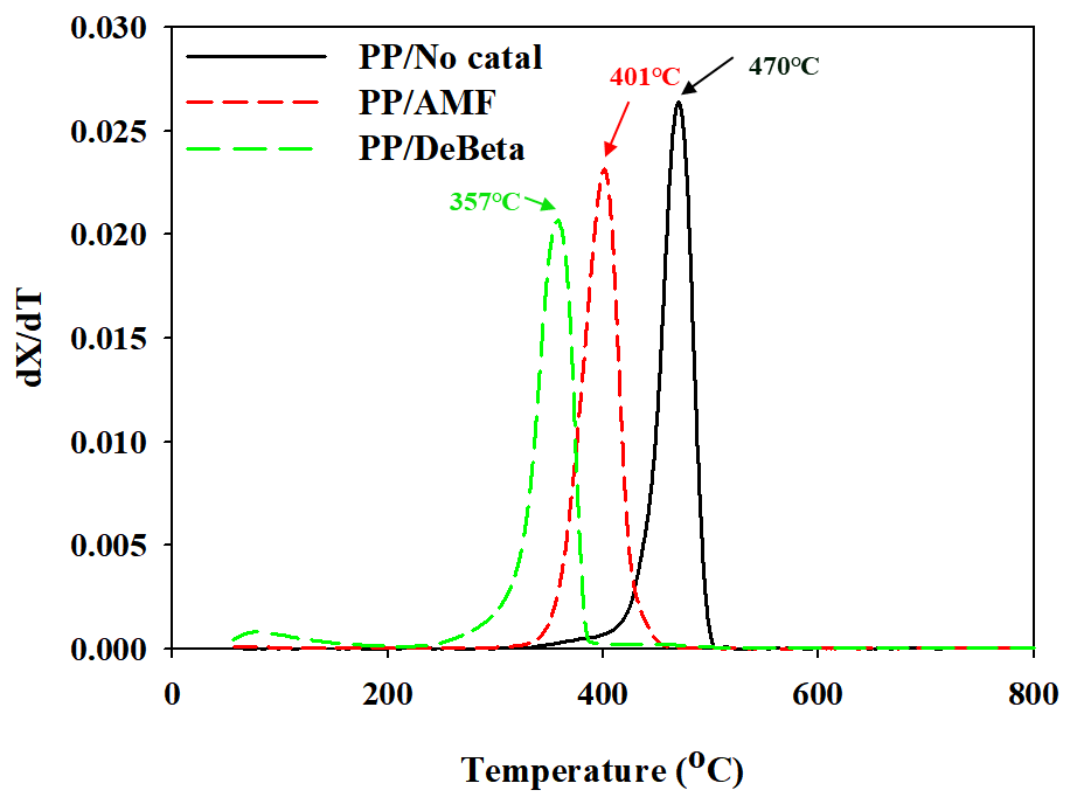

(b)

Figure 4. DTG curves of thermal and catalytic pyrolysis of (a) HDPE and (b) PP.

Non-catalytic DTG curves of HDPE and PP revealed different decomposition temperatures. The DTG peak temperatures of HDPE and PP were 501 and $470{ }^{\circ} \mathrm{C}$, respectively. Catalytic TGA of the plastics mixed with AMF and DeBeta showed lower decomposition temperatures than that of non-catalytic TGA. This suggests that mesoporous catalysts can decrease the decomposition temperature of plastics. The effectiveness of mesoporous catalysts on decreasing the polymer decomposition temperature and activation energy on the TGA of polymers were also reported [22]. Between the two catalysts, DeBeta was more effective in decreasing the decomposition temperatures of HDPE and PP than AMF. The decreased decomposition temperature of plastics during non-isothermal TGA over a catalyst can be explained by the surface properties and acidity of the catalyst. An appropriate pore size for the diffusion of reactants to the catalyst pore and sufficiently high acidity for the cracking reaction are necessary for a decrease in the plastic degradation temperature 
using a catalyst. Although DeBeta had a smaller pore size than AMF, the decomposition of HDPE and PP over DeBeta, 409 and $357^{\circ} \mathrm{C}$, respectively, were also much lower than those over AMF (441 and $401{ }^{\circ} \mathrm{C}$, respectively), indicating the unrestricted diffusion of reactant molecules into the pores of both catalysts, due to the presence of mesopores in both catalysts. This suggests that the catalytic reaction efficiency was increased because the plastics pyrolyzates could diffuse into the mesopores, and access the acid sites easily [23]. Therefore, the main factor for the further-decreased decomposition of all plastics, using DeBeta, can be explained by its much higher acidity than that of AMF.

Figure 5 presents the chromatograms acquired from the catalytic Py-GC/MS analysis of HDPE and PP over different amounts of DeBeta and AMF. According to previous reports, the pyrograms of HDPE and PP are consistent with hydrocarbons having a wide carbon number distribution, more than C40. In addition, the chromatograms acquired from the catalytic Py-GC/MS analysis of HDPE and PP over AMF and DeBeta had a much narrower carbon range. This suggests that both catalysts have catalytic cracking efficiency. On the other hand, the CP products over AMF and DeBeta were different because DeBeta had higher acidity than AMF as shown in Figure 3. For example, a large amount of high molecular hydrocarbons were still observed on the chromatogram as a result of the CP of HDPE over AMF, even though these heavy hydrocarbons peaks decreased with increasing number of small molecular hydrocarbons by increasing the catalyst to plastic ratio from $1 / 1$ to $10 / 1$. This indicates that the overall efficiency for the formation of light hydrocarbons can be increased by increasing the amount of catalyst, even though AMF cannot provide a sufficiently high catalytic cracking efficiency. Generally, the thermal pyrolysis of plastics produces high molecular weight hydrocarbons, such as wax, by a radical mechanism via $\mathrm{C}-\mathrm{C}$ bond breaking. $\mathrm{CP}$ degrades plastics via a carbenium ion mechanism. In addition, the $\mathrm{CP}$ of plastic produces branched hydrocarbons due mainly to the rearrangement of the carbocation in the carbenium ion mechanism. Therefore, the main reaction mechanism of the $\mathrm{CP}$ of plastics using AMF can be considered to be the carbenium ion mechanism [24]. 

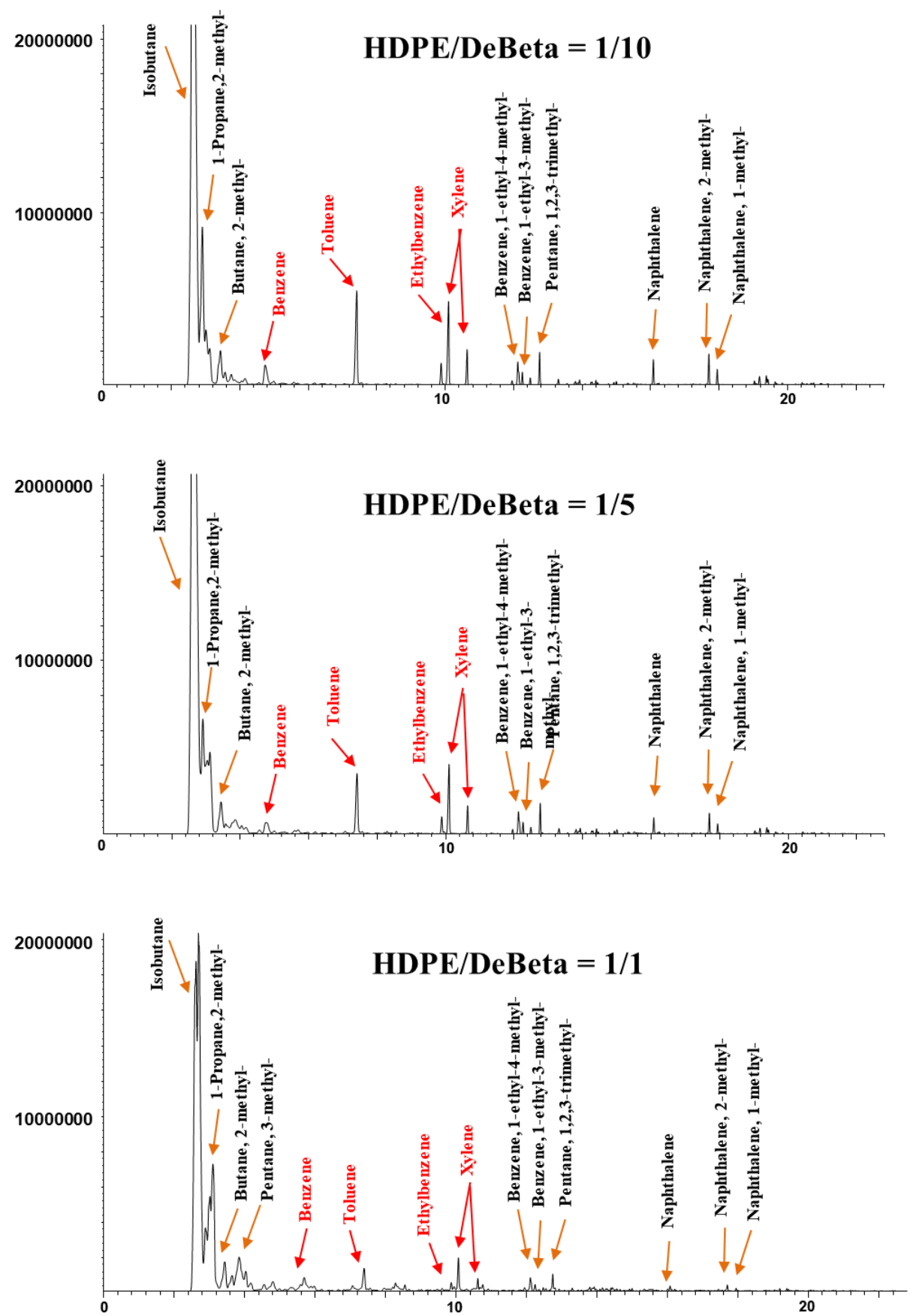

(a)

Figure 5. Cont. 

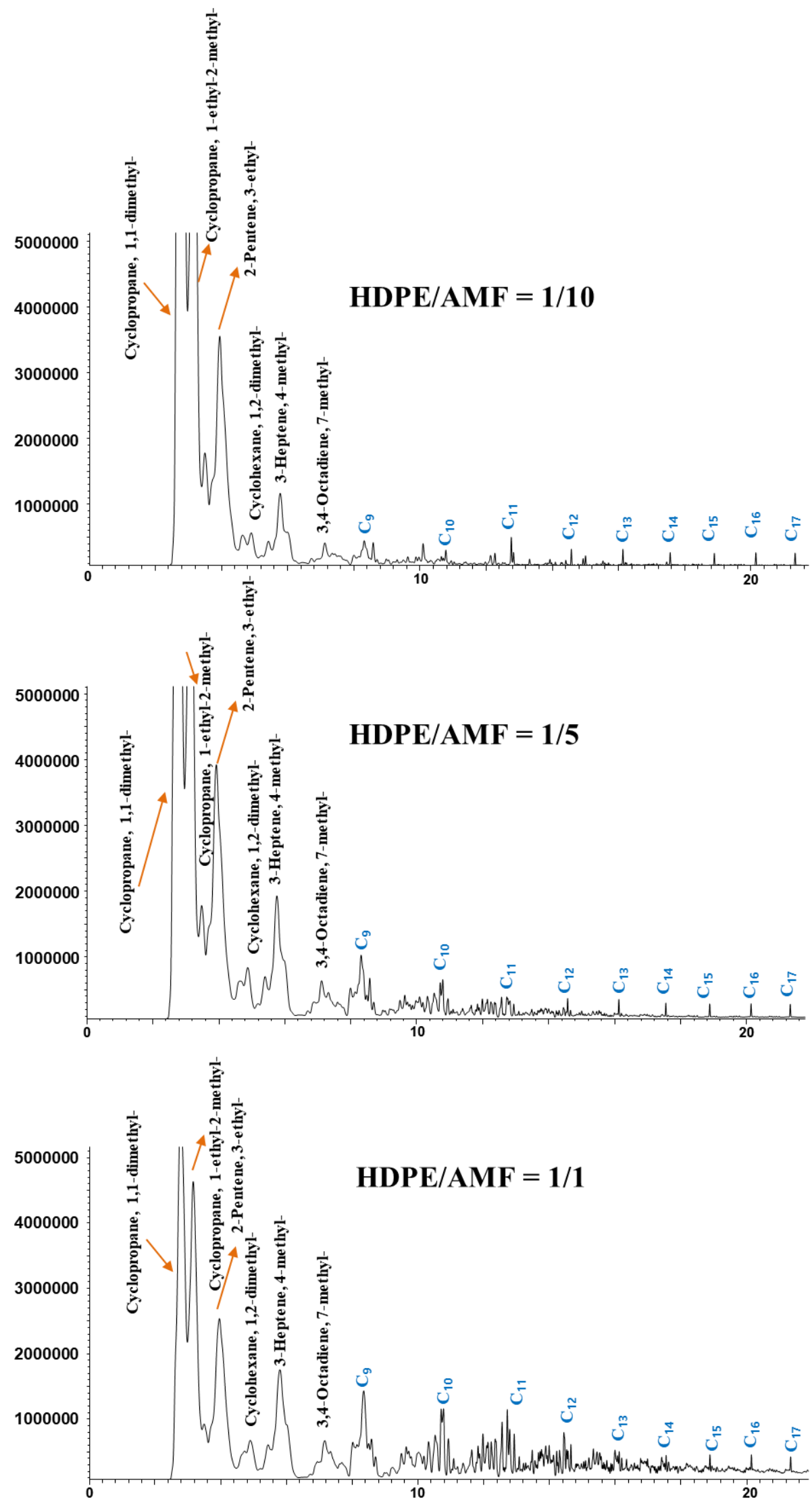

(b)

Figure 5. Cont. 

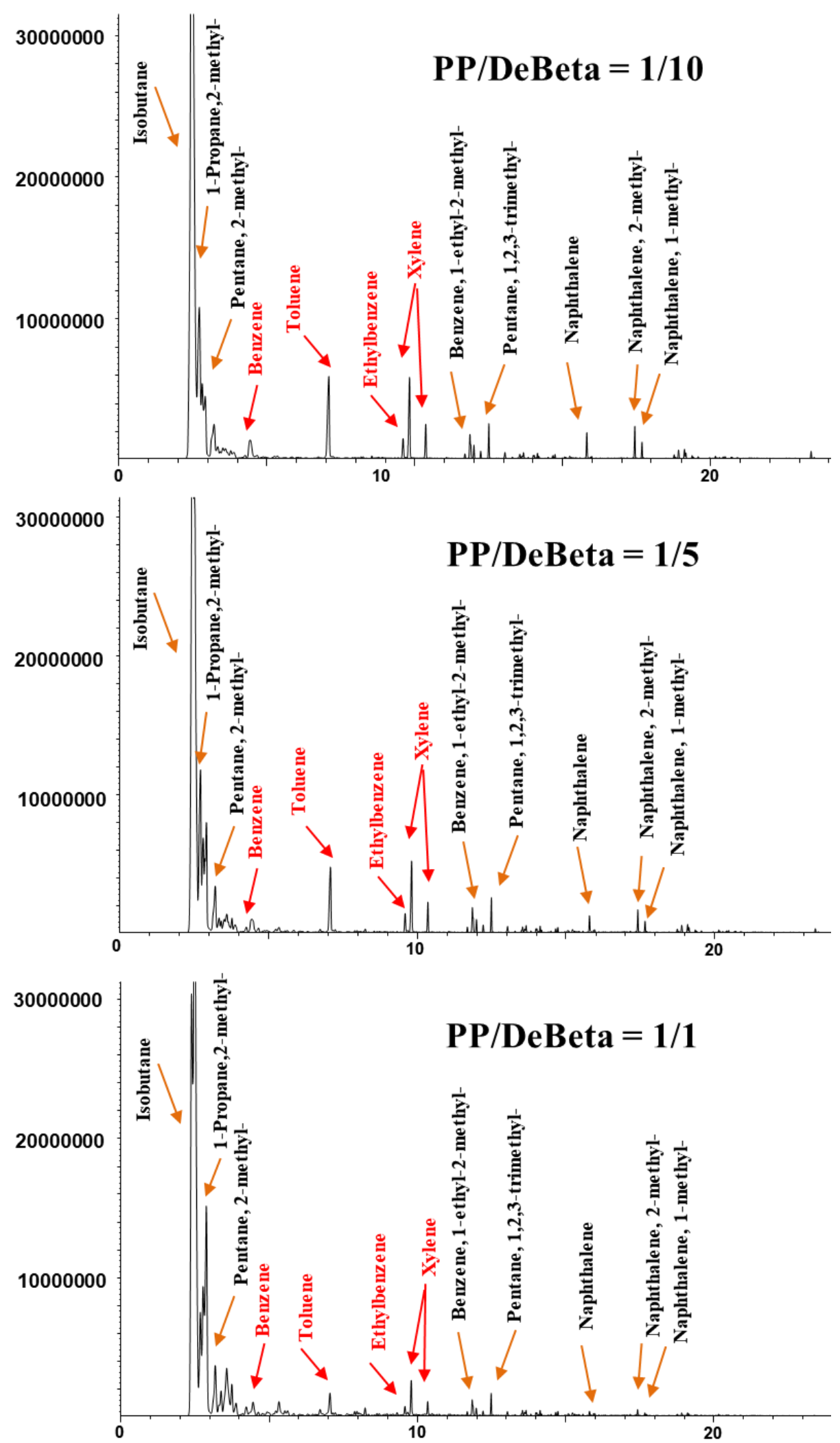

(c)

Figure 5. Cont. 

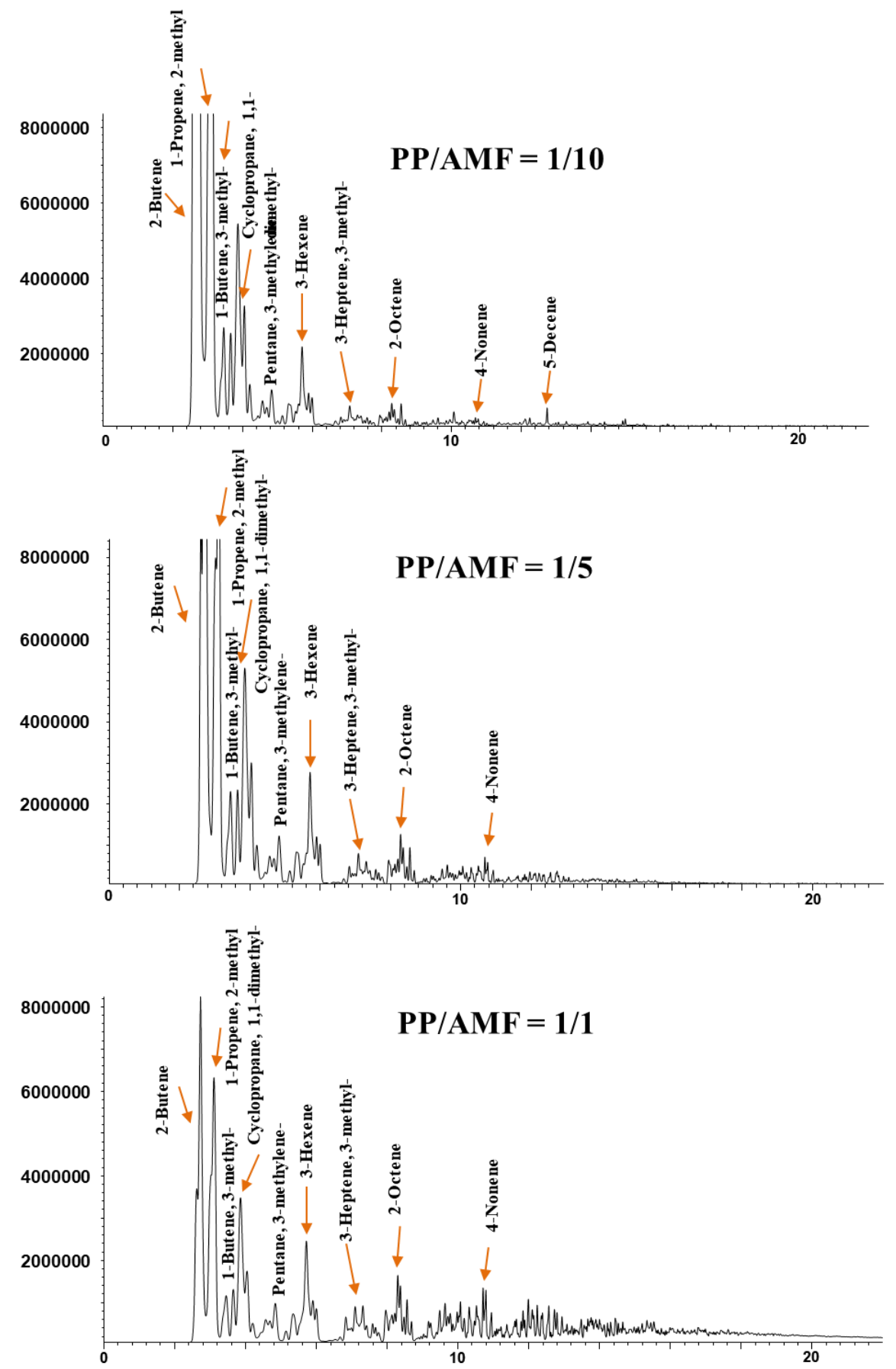

(d)

Figure 5. Chromatograms of the catalytic pyrolysis of (a) HDPE over DeBeta, (b) HDPE over AMF, (c) PP over DeBeta and (d) PP over AMF.

Heavy aliphatic hydrocarbons were not detected on the chromatogram acquired from the $\mathrm{CP}$ of HDPE over DeBeta, even at small catalyst to plastic ratios $(1 / 1)$, and light isoparaffins and aromatic hydrocarbons, such as benzene, toluene, ethylbenzene, and xylene (BTEXs), were the main products, owing to higher acidity. At a higher catalyst to plastic ratio, the peak intensities for aromatic hydrocarbons were increased further. The reason for the high cracking efficiency and monoaromatics formation over DeBeta can be attributed to the high acidity of DeBeta and the presence of micropores in this catalyst. The CP of HDPE and PP over DeBeta also revealed a higher reaction efficiency on 
cracking and aromatics formation compared to that over AMF because DeBeta had not only high acidity, but also mesopore structure. Therefore, DeBeta having micro/mesopores and high acidity can produce aromatic hydrocarbons more efficiently than AMF via scission, isomerization, cyclisation, hydrogen transfer, and oligomerization $[12,25,26]$.

Figure 6 shows the yields of aromatic hydrocarbons produced from the CP of HDPE and PP over different amounts of DeBeta. The yields of aromatic hydrocarbons, BTEXs, other monocyclic aromatic hydrocarbons (MAHs), and polycyclic aromatic hydrocarbons (PAHs), were increased by applying a higher catalyst to plastic ratio. Although DeBeta had high surface area and large pore size with strong acid sites, plastic pyrolyzates, such as hydrocarbons, still remained in pyrolysis oil without being converted to aromatic hydrocarbons. With increased catalyst-to-plastic ratio, plastic pyrolyzates could access acid sites with higher probability, leading to an enhancement in the production of aromatic hydrocarbon. Interestingly, the BETX selectivity in the oil produced from the $\mathrm{CP}$ of plastics over DeBeta was much higher than that of other MAHs and PAHs. In particular, a large amount of toluene was produced from the $\mathrm{CP}$ of plastics using DeBeta. Between the two plastics, PP showed a higher efficiency on the production of aromatic hydrocarbons than HDPE, because PP has branched carbon chains that can be decomposed more easily by the catalytic reaction than PEs [12].

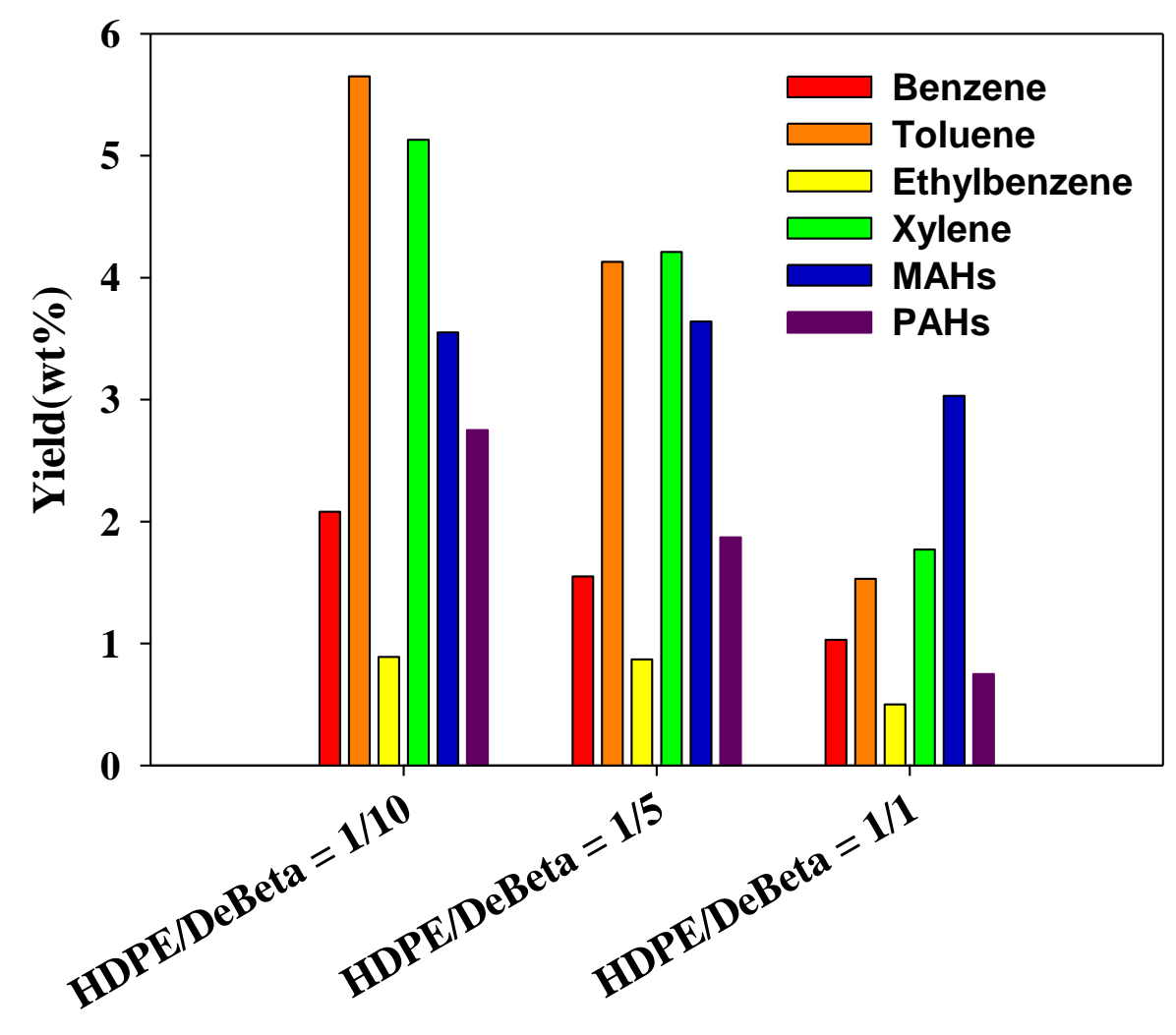

(a)

Figure 6. Cont. 


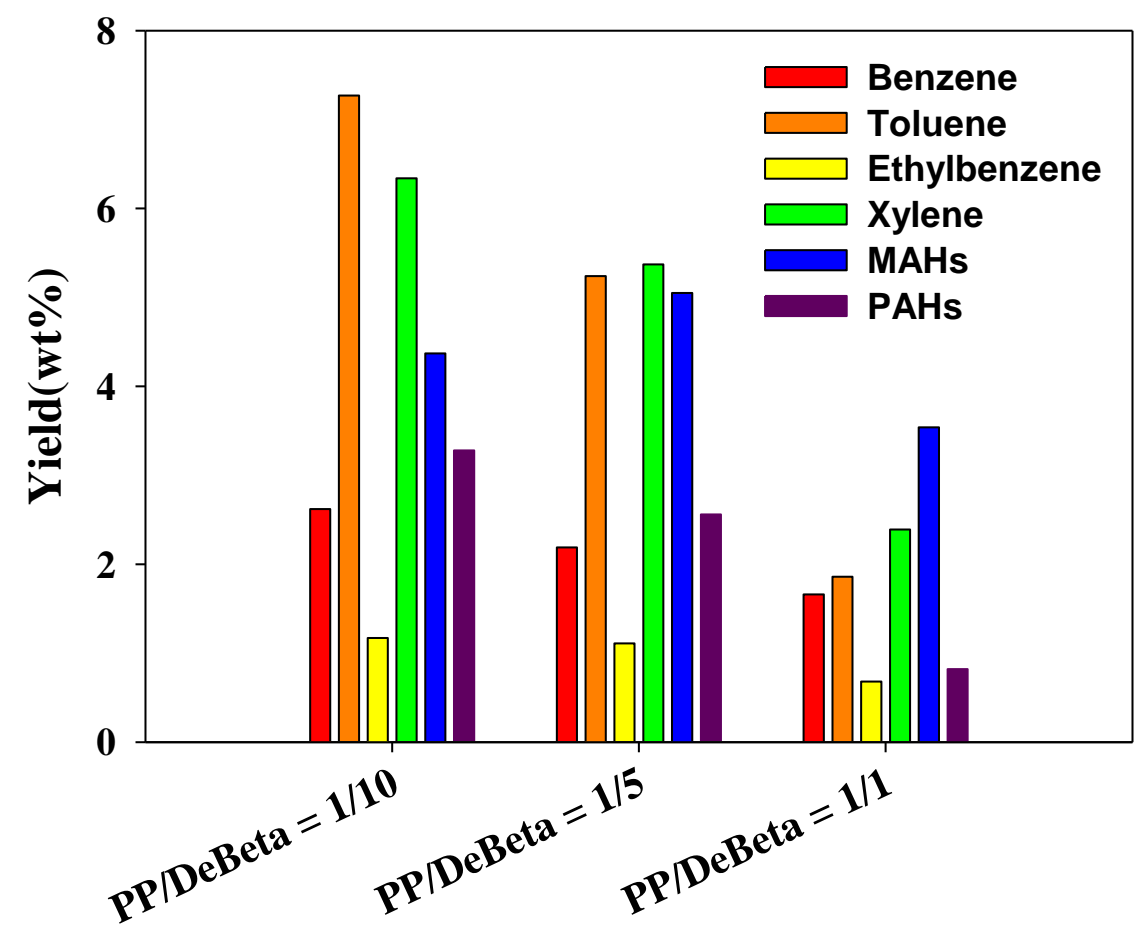

(b)

Figure 6. Yield of aromatic hydrocarbons produced from catalytic pyrolysis of (a) HDPE and (b) PP using DeBeta.

\section{Materials and Methods}

\subsection{Plastics and Catalysts}

HDPE and PP having the particle size between 500 and $700 \mu \mathrm{m}$ were obtained from a local chemical company and kept in a desiccator before the analysis.

\subsection{Catalysts}

Al-MSU-F(AMF) purchased from Sigma-Aldrich (St. Louis, MO, USA) has a cellular foam framework [25]. DeBeta was prepared by the desilication of Beta using $\mathrm{NaOH}$ solution $[27,28]$. For this, a commercial Beta $\left(\mathrm{SiO}_{2} / \mathrm{Al}_{2} \mathrm{O}_{3}=38\right)$ was stirred in $0.2 \mathrm{M} \mathrm{NaOH}$ solution at $60{ }^{\circ} \mathrm{C}$ for $30 \mathrm{~min}$, and ion exchanged as ammonium form in $0.1 \mathrm{M} \mathrm{NH}_{4} \mathrm{NO}_{3}$ solution. The prepared catalysts were calcined at $550{ }^{\circ} \mathrm{C}$ for $3 \mathrm{~h}$ before the analysis.

The powder X-ray diffraction analysis using XRD (Rigaku D/Max-2000, Rigaku, Tokyo, Japan, a $\mathrm{Cu} \mathrm{K} \alpha$ X-ray at $40 \mathrm{kV}, 30 \mathrm{~mA}$ ) was performed to confirm the zeolite structure of Beta and DeBeta. The BET pore size and surface area of each catalyst were measured by Micromeritics ASAP 2000 (Norcross, GA, USA) and determined by Brunauer-Emmett-Teller (BET) and Barrett-Joyner-Halenda (BJH) model. To compared the acidity of catalysts, temperature-programmed desorption of ammonia $\left(\mathrm{NH}_{3}-\mathrm{TPD}\right)$ analysis was also performed using a BELCAT-M instrument (BEL Japan Inc., Toyonaka, Japan) connected to a thermal conductivity detector (TCD).

\subsection{Thermal Decomposition Analysis}

About $6 \mathrm{mg}$ of HDPE and PP was heated by a non-isothermal temperature program, from $30{ }^{\circ} \mathrm{C}$ temperature to $800^{\circ} \mathrm{C}$ at $20^{\circ} \mathrm{C} / \mathrm{min}$ of heating rate under $60 \mathrm{~mL} / \mathrm{min}$ of nitrogen atmosphere, using a TGA (Pyris Diamond, Perkin-Elmer, Waltham, MA, USA) [13]. For the catalytic TG analysis, $6 \mathrm{mg}$ of catalyst was mixed with plastics and the same temperature program was applied. 


\subsection{Py-GC/MS Measurement}

Microscale pyrolysis reactor (Py-3030D, Frontier laboratories, Fukushima, Japan) connected to a GC/MS (7890A/5975C, Agilent Technologies, Santa Clara, CA, USA) was used for the isothermal and catalytic flash pyrolysis of plastics and their product analysis. For non-catalytic pyrolysis (non-CP), $0.8 \mathrm{mg}$ of plastic sample was pyrolyzed at $500{ }^{\circ} \mathrm{C}$, and the product vapor was analyzed in the GC at the same time according to the analysis conditions shown in Table 1. For the CP, different amount of catalyst, $0.8,4$, and $8 \mathrm{mg}$, was mixed with $0.8 \mathrm{mg}$ of plastic sample to know the effect of catalyst to plastic ratio $(1 / 1,5 / 1$, and $10 / 1)$, and pyrolyzed at the same conditions applied to non-catalytic Py-GC/MS analysis.

Table 1. Thermal and catalytic Py-GC/MS analysis condition.

\begin{tabular}{|c|c|c|}
\hline \multirow{2}{*}{ Pyrolyzer } & Furnace & $500{ }^{\circ} \mathrm{C}$ \\
\hline & Interface & $320^{\circ} \mathrm{C}$ \\
\hline \multirow{3}{*}{ GC } & Inlet & Temperature, $320^{\circ} \mathrm{C}$, Split ratio, $100: 1$ \\
\hline & Oven & $40^{\circ} \mathrm{C}(4 \mathrm{~min}) \rightarrow 10^{\circ} \mathrm{C} \min \rightarrow 320^{\circ} \mathrm{C}(10 \mathrm{~min})$ \\
\hline & MS interface & $320^{\circ} \mathrm{C}$ \\
\hline \multirow{2}{*}{ MS } & Emission current & $70 \mathrm{eV}$ \\
\hline & Scan range & $m / z 29-550$ \\
\hline
\end{tabular}

\section{Conclusions}

Two kinds of mesoporous catalysts, AMF and DeBeta, revealed the catalytic effect on the pyrolysis of HDPE and PP. The decomposition temperatures of all plastics were decreased by the use of both catalysts. Compared to AMF, DeBeta led the much lower decomposition temperature of the plastics than AMF, due to its proper pore size and much higher acidity. The $\mathrm{CP}$ of plastics over both catalysts produced smaller molecular hydrocarbons, and the overall efficiency of the catalyst on the cracking of plastics and aromatics formation were different, due to their physicochemical properties. Owing to the proper pore size and high acidity of DeBeta, the $\mathrm{CP}$ of plastics over DeBeta produced a much larger amount of light hydrocarbons and aromatic hydrocarbons, than those over AMF.

Author Contributions: Conceptualization, Y.-K.P.; Data curation, H.W.L.; Formal analysis, H.W.L.; Investigation, H.W.L.; Methodology, Y.-K.P.; Supervision, Y.-K.P.; Validation, Y.-K.P.; Visualization, Y.-K.P.; Writing一original draft, H.W.L.; Writing—review \& editing, Y.-K.P.

Funding: This work was supported by the National Research Foundation of Korea (NRF) grant funded by the Korea government (MSIT) (No. 2018R1A2B2001121).

Conflicts of Interest: The authors declare no conflict of interest.

\section{References}

1. Han, T.U.; Kim, Y.M.; Watanabe, A.; Terame, N.; Kim, S.D. Pyrolysis kinetic analysis of poly(methyl methacrylate) using evolved gas analysis-mass spectrometry. Korean J. Chem. Eng. 2017, 34, 1214-1221. [CrossRef]

2. Upare, D.P.; Park, S.; Kim, M.S.; Kim, J.; Lee, D.; Lee, J.; Chang, H.; Choi, W.; Choi, S.; Jeon, Y.P.; et al. Cobalt promoted Mo/beta zeolite for selective hydrocracking of tetralin and pyrolysis fuel oil into monocyclic aromatic hydrocarbons. J. Ind. Eng. Chem. 2016, 35, 99-107. [CrossRef]

3. Al-Salem, S.M.; Antelava, A.; Constantinou, A.; Manos, G.; Dutta, A. A review on thermal and catalytic pyrolysis of plastic solid waste (PSW). J. Environ. Manag. 2017, 197, 177-198. [CrossRef] [PubMed]

4. Parthasarathy, P.; Choi, H.S.; Park, H.C.; Hwang, J.G.; Yoo, H.J.; Lee, B.K.; Upadhyay, M. Influence of process conditions on product yield of waste tyre pyrolysis-A review. Korean J. Chem. Eng. 2016, 33, 2268-2286. [CrossRef] 
5. Yang, W.S.; Lee, J.E.; Seo, Y.C.; Lee, J.S.; Yoo, H.M.; Park, J.K.; Park, S.W.; Lee, K.B.; Kim, W.H. Utilization of automobile shredder reside (ASR) as a reducing agent for the recovery of black copper. Korean J. Chem. Eng. 2016, 33, 1267-1277. [CrossRef]

6. Sim, J.W.; Kim, S.S. Recovery of polyethylene terephthalate monomer over $\mathrm{Cu}$ or $\mathrm{Mn} / \mathrm{r}-\mathrm{Al}_{2} \mathrm{O}_{3}$ Catalysts. Appl. Chem. Eng. 2017, 28, 485-489.

7. Sharuddin, S.D.A.; Abnisa, F.; Daud, W.M.A.W.; Aroua, M.K. A review on pyrolysis of plastic wastes. Energy Conv. Manag. 2016, 115, 308-326. [CrossRef]

8. Choi, S.K.; Choi, Y.S.; Kim, S.J.; Han, S.Y. Numerical study on the evaporation characteristics of biocrude-oil produced by fast pyrolysis. Appl. Chem. Eng. 2016, 27, 646-652. [CrossRef]

9. Shafaghat, H.; Rezaei, P.S.; Ro, D.; Jae, J.; Kim, B.S.; Jung, S.C.; Sung, B.H.; Park, Y.K. In-situ catalytic pyrolysis of lignin in a bench-scale fixed bed pyrolyzer. J. Ind. Eng. Chem. 2017, 51, 206-215. [CrossRef]

10. Lee, H.; Kim, Y.M.; Lee, I.G.; Jeon, J.K.; Jung, S.C.; Chung, J.D.; Choi, W.G.; Park, Y.K. Recent advances in the catalytic hydrodeoxygenation of bio-oil. Korean J. Chem. Eng. 2017, 54, 447-453. [CrossRef]

11. Lee, Y.; Shafaghat, H.; Kim, J.K.; Jeon, J.K.; Jung, S.C.; Lee, I.G. Upgrading of pyrolysis bio-oil using $\mathrm{WO}_{3} / \mathrm{ZrO}_{2}$ and Amberlyst catalysts: Evaluation of acid number and viscosity. Korean J. Chem. Eng. 2017, 34, 2180-2187. [CrossRef]

12. Kassargy, C.; Awad, S.; Burnens, G.; Kahine, K.; Tazerout, M. Gasoline and diesel-like fuel production by continuous catalytic pyrolysis of waste polyethylene and polypropylene mixtures over USY zeolite. Fuel 2018, 224, 764-773. [CrossRef]

13. Zhang, X.; Lei, H.; Yadavalli, G.; Zhu, L.; Wei, Y.; Liu, Y. Gasoline-range hydrocarbons produced from microwave-induced pyrolysis of low-density polyehtylene over ZSM-5. Fuel 2015, 144, 33-42. [CrossRef]

14. Auxilio, A.R.; Choo, W.; Kohli, I.; Srivatsa, S.C.; Bhattacharya, S. An experimental study on thermo-catalytic pyrolysis of plastic waste using a continuous pyrolyzer. Waste Manag. 2017, 67, 143-154. [CrossRef] [PubMed]

15. Sipra, A.T.; Gao, N.; Sarwar, H. Municipal solid waste (MSW) pyrolysis for bio-fuel production: A review of effects of MSW components and catalysts. Fuel Process. Technol. 2018, 175, 131-147. [CrossRef]

16. Miandad, R.; Barakat, M.A.; Aburiazaiza, A.S.; Rehan, M.; Nizami, A.S. Catalytic pyrolysis of plastic waste: A review. Process Saf. Environ. Protect. 2016, 102, 822-838. [CrossRef]

17. Lopez, A.; de Marco, I.; Caballero, B.M.; Laresgoiti, M.F.; Adrados, A.; Aranzabal, A. Catalytic pyrolysis of plastic wastes with two different types of catalysts: ZSM-5 zeolite and Red Mud. Appl. Catal. B Environ. 2011, 104, 211-219. [CrossRef]

18. Sun, K.; Huang, Q.; Ali, M.; Chi, Y.; Yan, J. Producing Aromatic-Enriched Oil from Mixed Plastics Using Activated Biochar as Catalyst. Energy Fuel 2018, 32, 5471-5479. [CrossRef]

19. Ratnasari, D.K.; Nahil, M.A.; Williams, P.T. Catalytic pyrolysis of waste plastics using staged catalysis for production of gasoline range hydrocarbon oils. J. Anal. Appl. Pyrolysis 2017, 124, 631-637. [CrossRef]

20. Santos, B.P.S.; Almeida, D.; Fatima, M.; Marques, V.; Henriques, C.A. Petrochemical feedstock from pyrolysis of waste polyethylene and polypropylene using different catalysts. Fuel 2018, 215, 515-521. [CrossRef]

21. McGlone, J.; Priecel, P.; Via, L.D.; Majdal, L.; Lopez-Sanchez, J.A. Desilicated ZSM-5 zeolites for the production of renewable p-Xylene via Diels-Alder cycloaddition of dimethylfuran and ethylene. Catalysts 2018, 8, 258. [CrossRef]

22. Kim, Y.M.; Jae, J.; Kim, B.S.; Hong, Y.; Jung, S.C.; Park, Y.K. Catalytic co-pyrolysis of torrefied yellow poplar and high-density polyethylene using microporous HZSM-5 and mesoporous Al-MCM-41 catalysts. Energy Conv. Manag. 2017, 149, 966-973. [CrossRef]

23. Serrano, D.P.; Aguado, J.; Escola, J.M.; Rodriguez, J.M.; Miguel, F.S. An investigation into the catalytic cracking of LDPE using Py-GC/MS. J. Anal. Appl. Pyrolysis 2005, 74, 370-378. [CrossRef]

24. Ma, C.; Yu, J.; Wang, B.; Song, Z.; Zhou, F.; Xiang, J.; Hu, S.; Sun, L. Influence of zeolites and mesoporous catalysts on catalytic pyrolysis of brominated Acrylonitrile-Butadiene-Styrene (Br-ABS). Energy Fuel 2016, 30, 4635-4643. [CrossRef]

25. Pattiya, A.; Titiloye, J.O.; Bridgwater, A.V. Evaluation of catalytic pyrolysis of cassava rhizome by principal component analysis. Fuel 2010, 89, 244-253. [CrossRef]

26. Corma, A.; Orchilles, A.V. Current views on the mechanism of catalytic cracking. Microporous Mesoporous Mater. 2000, 35-36, 21-30. [CrossRef] 
27. Lee, H.; Kim, Y.M.; Jung, K.B.; Jae, J.; Jung, S.C.; Jeon, J.K.; Park, Y.K. Catalytic hydrodexoygenation of Geodae-Uksae pyrolysis oil over Ni/desilicated HZSM-5. J. Clean Prod. 2018, 174, 763-770. [CrossRef]

28. Hong, Y.; Lee, Y.; Rezaei, P.S.; Kim, B.S.; Jeon, J.K.; Jae, J.; Jung, S.C.; Kim, S.C.; Park, Y.K. In-situ catalytic copyrolysis of cellulose and polypropylene over desilicated ZSM-5. Catal. Today 2017, 293-294, 151-158. [CrossRef]

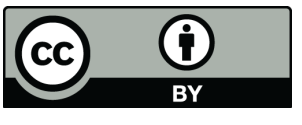

(c) 2018 by the authors. Licensee MDPI, Basel, Switzerland. This article is an open access article distributed under the terms and conditions of the Creative Commons Attribution (CC BY) license (http:/ / creativecommons.org/licenses/by/4.0/). 